\title{
Voluntary Control of Auditory Hallucinations: \\ Phenomenology to Therapeutic Implications
}

\section{Running title: Voluntary Control of Auditory Hallucinations}

Ariel Swyer ${ }^{1}$ and Albert R. Powers III ${ }^{2 *}$

${ }^{1}$ Department of Behavioral Sciences, York College / CUNY, Jamaica, NY

${ }^{2}$ Department of Psychiatry and the Connecticut Mental Health Center, Yale University, New Haven CT

*Correspondence should be addressed to:

Albert R. Powers III, M.D., Ph.D.

Connecticut Mental Health Center

34 Park Street

New Haven, CT 06511

P: 203-974-7329

albert.powers@yale.edu

Word Count (text body): 5158

Abstract word count: 196 


\begin{abstract}
Auditory verbal hallucinations $(\mathrm{AVH})$ have traditionally been thought to be outside the influence of conscious control. However, recent work with voice-hearers makes clear that both treatmentseeking and non-treatment seeking voice-hearers may exert varying degrees of control over their voices. Evidence suggests that this ability may be a key factor in determining health status, but little systematic examination of control in AVH has been carried out. This review provides an overview of the research examining control over AVH in both treatment-seeking and nontreatment-seeking populations. We first examine the relationship between control over AVH and health status as well as the psychosocial factors that may influence control and functioning. We then link control to various cognitive constructs that appear to be important for voice-hearing. Finally, we reconcile the possibility of control with the field's current understanding of the proposed cognitive, computational, and neural underpinnings of hallucinations and perception more broadly. Established relationships between control, health status, and functioning suggest that the development of control over AVH could increase functioning and reduce distress. A more detailed understanding of the discrete types of control, their development, and their neural underpinnings is essential for translating this knowledge into new therapeutic approaches.
\end{abstract}




\section{Introduction}

Faced with the seemingly unimodal nature of the pre-existing term vision, Esquirol (1845) first introduced the term hallucination to the nascent field of psychiatry as follows: "A person is said to labor under a hallucination or to be a visionary who has a thorough conviction of the perception of a sensation, when no external object, suited to excite this sensation, has impressed the senses"1. Others of the French school quickly adopted the definition ${ }^{2}$, which was carried forward by the major psychiatric textbook writers of the $20^{\text {th }}$ century, including Jaspers ${ }^{3}$ and $\mathrm{Ey}^{4}$, who required that a hallucination: 1) have the appearance of a sensory event; and 2) produce conviction in its reality ${ }^{5}$. Only in the late $20^{\text {th }}$ century did some in the field begin to define hallucinations as being necessarily outside of voluntary control. In their seminal book on the subject, Slade and Bentall ${ }^{6}$ added a third requirement, namely that hallucinations not be "susceptible to being voluntarily directed or controlled by those who experience [them]." This was in keeping with an understanding of hallucinations as being distinct from voluntary imagery ${ }^{7}$ or the pseudohallucinations of neurological illness, which, in addition to being amenable to initiation or interruption by will ${ }^{3}$, were described as often lacking the perceptual detail characterized by true hallucinations and necessarily occurring in the context of full insight into their unreality ${ }^{8}$.

Only recently have many researchers begun to recognize the possibility that phenomenologically-rich, real-seeming auditory-verbal hallucinations (AVH) can, in some cases, be voluntarily controlled. The advent of this work was made possible in part by the recognition that many of those who hear voices may never seek treatment ${ }^{9-19}$. Epidemiological studies suggest that $7-15 \%$ of the general population hears voices, at times regularly ${ }^{20-22}$, and only $20 \%$ of those who experience AVH go on to develop a psychotic disorder ${ }^{22}$. 
Some have suggested that all voice-hearing experiences lie on a continuum ${ }^{23}$, while others argue that the experiences of treatment-seeking and non-treatment-seeking voice-hearers are fundamentally different ${ }^{24}$, and still others suggest the possibility of multiple, potentially discontinuous continua ${ }^{25}$. AVH in treatment-seeking and non-treatment-seeking individuals tend to be similar in terms of low-level acoustic qualities such as loudness, location, duration, and location $^{26-28}$, but show key differences in higher-level, attributional characteristics such as interpretation of the voices' origins, their perceived malevolence, and their ability to be engaged meaningfully ${ }^{28-31}$.

Non-treatment-seeking voice-hearing populations also consistently endorse a higher degree of control over their experiences than their treatment-seeking counterparts ${ }^{12,28-30,32-43}$. Perhaps most strikingly, some individuals in non-treatment-seeking groups report an ability to control the onset and offset of their voices ${ }^{28,38,43}$, which may make the experience of living with these voices significantly less disruptive and distressing ${ }^{44}$. Further, narratives surrounding the development of these abilities highlight the possibility that they may be intentionally nurtured and developed over time $\mathrm{e}^{28,45,46}$.

Although control over AVH has been reported repeatedly in the literature, there has been little in-depth examination of its meaning, its development, or its cognitive, computational, and neural bases. Here we present an overview of the field's current understanding of control over AVH in both treatment-seeking and non-treatment-seeking populations. We begin by discussing the concept of control over AVH and the varieties of control seen in the literature. We then provide an overview of the relationship between control and functioning in voice-hearing populations, followed by an examination of the psychosocial and cognitive factors that appear to influence control. We then attempt to reconcile the possibility of control with the field's current 
understanding of the proposed cognitive, computational, and neural underpinnings of hallucinations and perception more broadly. Lastly, we consider therapeutic implications of the systematic study of control over AVH.

\section{Varieties of Control}

Control of AVH may be defined as an ability to voluntarily influence one's voice-hearing experience. It is clear from the literature that control over one's hallucinations, like hallucination itself $^{23,25}$, cannot be considered a unitary phenomenon. Rather, it appears to exist as a variety of abilities within a myriad of contexts. These abilities seem to fall into broad categories: direct control strategies and indirect control strategies (Figure 1). Indirect control strategies include those that influence the frequency or impact of one's voices by manipulating other related factors like attention. Direct control describes the ability to influence the onset and offset of these experiences by interacting with them more directly (e.g.., negotiating boundaries with the voices or telling the voices to go away ${ }^{43}$ ). The ability of some voice-hearers to exercise indirect control by using cognitive strategies to manipulate the impact of voice-hearing has served as the basis

for cognitive-behavioral approaches to psychosis for several decades ${ }^{47,48}$. However, the ability to directly control their onset and offset ${ }^{28,43,49}$ has not played a prominent role in traditional therapeutic approaches.

The literature surrounding control over hallucinations seldom specifies the type of control endorsed by participants, focusing instead on degree of perceived control endorsed by the participant on clinician-rated scales like the PSYRATS-AH ${ }^{50}$ (see Table 1). Potentially-related forms of cognitive control have also been assayed, but none have focused on control over 
hallucinations themselves ${ }^{51}$. The authors of the PSYRATS note that reliability of the PSYRATS control item is unusually low "due to the complexity of control as a construct." The authors go on to state that other instruments might better capture important determinants of control. We agree. We will argue that type and degree of endorsed control in voice-hearing populations should be defined carefully and specifically in the future, as these different types of control are likely subserved by different cognitive and neural mechanisms and may drive the development of vastly different treatment strategies.

Interestingly, different types of control appear to be present across a wide variety of voicehearers. Ability to control the onset and/or offset of voice-hearing through direct interaction with voices (direct control) appears to be endorsed frequently in those who interpret their voicehearing spiritually. Classic ethnographic studies by Murphy (1976) describe shamanistic practices among Inuits, comparing these with individuals recognized to be mentally ill in the same population. In making the distinction between these two groups, Murphy contends that any such distinction depends on "the degree to which they are controlled and utilized for a specific social function. The inability to control these experiences is what is meant by a mind out of order; when a mind is out of order it will not only fail to control sensory perception but will also fail to control behaviour." ${ }^{24}$ More recently, Powers and colleagues compared treatment-seeking individuals with AVH to self-identified clairaudient mediums and found that the latter population was more likely to report being able to summon or stop their AVH at will ${ }^{28}$. Similarly, a recent qualitative analysis of the experiences of ten British Spiritualists found that these individuals described a similar ability to "shut off" their voices in order to prevent them from interfering with their lives ${ }^{43}$. At least two other analyses report similar findings ${ }^{49,52}$. As one participant in a study of Spiritualist mediums described it: "When you're working, you're working, and when 
you're not, you're not. Say to the spirit that, you know, I'll be there Thursday at 7:30." ${ }^{92}$ Other work suggests that similar abilities may exist in non-treatment-seeking voice-hearers as a whole $^{38,53}$. In clinical populations, development of such direct control abilities has been reported in voice-hearers under guidance of the Hearing Voices Movement $(\mathrm{HVM})^{54,55}$ for decades.

Development of these abilities, while described briefly in small studies as requiring engagement and practice ${ }^{28,43}$ and implicitly acknowledged as being effortful in HVM guidelines ${ }^{54-56}$, have yet to be outlined in detail. The process by which these skills are fostered and developed carry obvious implications for the development of treatment based on these findings. In the next section, we begin to outline potential factors that may relate to the development of these abilities.

\section{Control, Health Status, and Functioning}

Regardless of type, degree of perceived control over the voice-hearing experience appears to be critical for the level of distress or dysfunction experienced by the voice-hearer. There have been several qualitative and quantitative studies directly comparing the experience of treatmentseeking and non-treatment-seeking populations with AVH in which control emerges as a distinguishing feature ${ }^{12,29,30,57}$. Birchwood and colleagues first identified that distress among patients with psychosis is potentially related to a perceived lack of control over their illness, including hallucinations ${ }^{58}$. After developing a comprehensive interview aimed at understanding the experiences of voice-hearers across the spectrum of illness, Romme and Escher reported that the majority of non-treatment-seeking voice-hearers (and some treatment-seekers) felt in control of their voices and experienced positive feelings about their content ${ }^{59}$.

Larøi and colleagues also identified perceived control as being potentially important for functioning in a study of 236 university students who also completed standard measures of 
hallucination frequency and intensity ${ }^{12}$, finding that affective response to hallucination and ability to control one's experiences were significantly associated. Daalman et al. (2011) compared patients and non-patients with AVH using the Psychotic Symptom Rating Scales Auditory Hallucinations Subscale (PSYRATS-AH) ${ }^{50}$ and found greater control over AVH in non-patients than in patients ${ }^{41}$. Similarly, Honig and colleagues interviewed patients and nonpatients with AVH and found that non-patients reported feeling more in control of their hallucinations than did their clinical counterparts ${ }^{42}$. These findings are extremely common in descriptions of non-treatment-seeking voice-hearers ${ }^{12,28-30,32-43}$ : a recent systematic review found that, of the 12 studies identified at that time to have compared perceived control in these two groups, 10 found non-treatment-seekers to have higher endorsed control, while 2 showed no difference $^{23}$. These differences in control are not always seen at the initial onset of AVH, with several studies of non-treatment seeking voice hearers finding that control is most frequently developed intentionally over time ${ }^{43,60}$.

\section{Psychosocial Influences}

\section{Locus of Control}

The degree to which one feels one has control over one's life in general, may play a role in the amount of control one experiences in regard to AVH. One measure of perceived control is the Locus of Control Scale, which measures the degree to which one perceives one's life to be controlled by outside forces (external) vs. by one's own choices and actions (internal) ${ }^{61}$. Studies have found that individuals with a psychotic disorder have a more external locus of control than the general population ${ }^{62}$. A longitudinal study found that a more external locus of control in adolescence strongly predicted a diagnosis of schizophrenia as an adult ${ }^{63}$. Relatedly, a qualitative 
study of voice-hearers both with and without a psychiatric diagnosis found that "developing a stronger sense of self and independence," was a crucial part of learning to live with voices ${ }^{64}$; a similar stance is explicitly endorsed by the $\mathrm{HVM}^{54-56}$.

A variety of factors may moderate the relationship between health status and locus of control. Those with clinical AVH have higher rates of depression than those with non-clinical AVH ${ }^{65,66}$, for instance, and depression is associated with a more external locus of control ${ }^{67}$. Post-traumatic stress disorder (PTSD) is also associated with a more external locus of control ${ }^{68}$. Both treatmentseeking and non-treatment-seeking AVH populations show higher levels of trauma than the general population $^{21,69}$, but those in the former group are more likely to have symptoms sufficient for diagnosis with PTSD ${ }^{39}$. Even among non-treatment-seeking voice-hearers, a more external locus of control is weakly predictive of severity of hallucinations and delusion-like beliefs $^{70}$.

\section{Engagement vs. Resistance}

It has been suggested that engagement, a willingness to interact with voices rather than attempting to ignore them or block them out, may be predictive of control over AVH. This involves various forms of interaction such as discussion, negotiation, and boundary setting, and often involves attributing some form of agency or personhood to voices. Engagement may be contrasted with resistance, or a refusal to acknowledge or interact with voices ${ }^{71,72}$. Several studies suggest that engagement with voices increases perceived control over voices and resistance decreases it. Peters and colleagues found that resistance to voices was correlated with higher levels of perceived omnipotence of those voices and greater degrees of distress related to them ${ }^{73}$. Others have reported that participants endorse higher degrees of control after undergoing 
spiritually-oriented training in which engagement with voices is encouraged ${ }^{49,52}$. Interestingly, participants also reported that ceasing to engage with voices made their experiences worse, further suggesting that engagement may be important for the maintenance of control. Along similar lines, one study of outpatients at a schizophrenia clinic found that attempts to resist or block voices led to greater perceived intrusiveness ${ }^{74}$, and another that a tendency to suppress or resist voices was associated with treatment-seeking status ${ }^{75}$.

Engagement can include compromise and boundary setting with voices. One study demonstrated that those without a diagnosed psychiatric disorder were more likely to have imposed boundaries on voices than those with a diagnosed psychiatric disorder ${ }^{76}$. Negotiation and compromise are another form of engagement. Luhrmann (2012) describes an individual whose voices instruct him to become a Buddhist. At the urging of his HVM group, he tells the voices that, each day, he will spend one hour reading about Buddhism and say one Buddhist prayer if they will leave him alone. The voices do begin to leave him alone, he is able to reduce his medication, and, ultimately, he returns to normal functioning ${ }^{60}$.

Others have examined the notion that the ways in which individuals interact with their voices may be similar to the dynamics of relationships with the people in their lives ${ }^{77}$. Related to the broader concept of locus of control, Birchwood and colleagues (2000) found that those who related to their voices from a position of powerlessness and subordination were more distressed by them than those who did not ${ }^{78}$. Hayward (2003) found that those who felt distressed by their voices were likely to feel powerless in relation to them and, furthermore, reacted to this by seeking distance from their voices ${ }^{77}$. Qualitative research has also found that, for some voicehearers, ignoring voices for long periods of time can make them louder and perceived more externally ${ }^{79}$. Overall, then, it appears that suppression of voices is correlated with negative 
outcomes and engagement with positive outcomes (although, see ${ }^{80}$ ). This relationship could be related to the tendency for thoughts one has attempted to express to become more cognitively available and further strain already limited cognitive inhibitory resources, as proposed by $\operatorname{Badcock}^{81}$.

\section{Beliefs about Voices}

The impact of voices on one's sense of control, as well as overall functioning, may be influenced by voice-hearers' beliefs about these voices and the amount of power that they may exert ${ }^{82}$. A tendency to appraise AVH as powerful has been shown to correlate with likelihood of following command hallucinations ${ }^{83}$, and treatment-seeking voice-hearers report more negative beliefs about the danger and uncontrollability of voices ${ }^{84}$. The explanatory framework one applies to understand one's voices also appears to have an impact on one's perceived level of direct control over AVH. Qualitative work suggests that learning to view voice hearing experiences within a spiritualist framework may lead to relief from distress associated with these voices ${ }^{43}$.

\section{Metacognition}

The ways in which individuals respond to their thoughts and AVH may interact with control over them. Brett and colleagues found that metacognitive beliefs regarding a need for control were associated with more negative responses to anomalous experiences ${ }^{85}$. A follow-up study used the Meta-Cognitions Questionnaire (MCQ) ${ }^{86}$ to demonstrate significantly higher levels of metacognition concerning a need for control in clinical versus non-clinical voice-hearers ${ }^{87}$. It may be that the need for control over one's own thoughts is related to resistance to AVH, which has also been shown to be negatively correlated with control over AVH and positive health outcomes. This further suggests that comorbid factors such as depression may play a significant 
role in differentiating treatment-seeking and non-treatment-seeking populations with AVH.

\section{Intentional Inhibitory Control}

Several studies have found that AVH is associated with decreased intentional inhibition ${ }^{51,88}$. Those with AVH do not, however, differ from non-hallucinating controls on measures of automatic $^{51}$ or interference control ${ }^{89}$. Proneness to auditory hallucinations is correlated with deficits in intentional inhibition, in both those with schizophrenia ${ }^{88}$ and healthy individuals with a high predisposition to hallucination ${ }^{51}$. The degree of intentional inhibitory dysfunction has also been found to be correlated with the frequency of auditory hallucinations in patients with schizophrenia $^{88}$. Future work should explicitly examine the relationship between ability to control AVH both directly and indirectly and intentional inhibitory control.

\section{Other Factors}

Spiritually-oriented voice-hearers may employ other techniques to promote development of control over AVH. Mediums may use a "spirit guide," for instance, to help them manage the voices $^{28,52}$. Calling in spiritual help was also found to be a useful technique for controlling voices in a study of voice-hearers both with and without a psychiatric diagnosis ${ }^{90}$. This study, which utilized grounded theory to qualitatively analyze the participants' experiences of voice hearing, also found that visualization was utilized to control voices: some participants reported visualizing an energy field around them which the voices couldn't cross. In Taylor and Murray's qualitative study of mediums, participants describe several techniques which helped them gain control over voices, including meditation ${ }^{52}$. Another participant describes a visualization exercise, consisting of imagining a light around her which the voices cannot penetrate as helping her to control the voices. A more focused analysis of these techniques and their potential to 
facilitate direct control over AVH is needed.

The need for control over one's thoughts may be influenced by cultural assumptions about the mind. For example, in a culture that assumes that the mind is not permeable, hallucinations would represent a more radical rupture of self and their uncontrollable nature would be more threatening. Indeed, participants with psychosis in India and Ghana, where boundaries of the self may be more permeable ${ }^{91}$, have been reported to be less disturbed by their experiences and this lack of distress seemed linked to a lesser need for control $^{92}$.

\section{Potential Cognitive, Computational, and Neural Mechanisms}

If voice-hearers can exert some degree of control over their experiences with AVH, how might this work in the context of what we understand to be the potential cognitive, computational, and neural mechanisms underlying AVH? We briefly consider the implications of control over hallucinations for the mechanisms that may produce them, taking into account current thinking on the relationship between perception and action as well as popularly-held schools of thought on the computational underpinnings of hallucinations.

Conceptualization of hallucinations as uninhibited, externalized thoughts fits well with some methods of control outlined above. One popular account of AVH views these phenomena as a disturbance of corollary discharge, a process by which information on planned, self-generated actions is used to predict the sensory consequences of those actions. Intact corollary discharge results in an attenuation of the somatosensory response arising as a consequence of one's own actions, for example: reaching out to touch a ball with one's hand generates a much less robust somatosensory response than if the ball were to hit one's hand. Thus, extant knowledge about the location and movements of one's own body allows for prediction and partial cancellation of 
the sensory consequences of one's actions, and the absence of such a cancellation implies that these sensations are the result of being acted upon rather than acting. These processes have been heavily implicated in causal inference ${ }^{93}$. It has been proposed that a failure to predict the sensory consequences of one's actions could lead to misattribution of inner speech to an external source ${ }^{94,95}$. Indeed, people with schizophrenia fail to predict the sensory consequences of their actions in somatosensory ${ }^{96}$, visual ${ }^{97-99}$, and auditory ${ }^{95,100-103}$ sensory modalities. Some have hypothesized that failure to predict the sensory or neural consequences of internal speech may produce hallucinations, taking as supporting evidence the smaller mismatch negativity (MMN) amplitudes and a host of other failures of prediction typically seen in schizophrenia ${ }^{94,95}$ (for review, see ${ }^{104}$ ).

Indirect control strategies shown to reduce the impact of voices via attentional allocation may serve to shift focus away from internally-generated thought patterns considered to be involved in the generation of AVH. This may be related to general cognitive control abilities. Research has found that treatment-seeking voice-hearers experience more intrusive thoughts than those with non-clinical $\mathrm{AVH}^{105}$ and that intentional inhibition - the ability to block unwanted thoughts from arising - is related to propensity to hallucinate in the general population ${ }^{53}$ and severity of hallucinations in clinical groups ${ }^{106}$. Others have similarly shown that patients with schizophrenia demonstrated less inhibitory control over irrelevant memories than healthy controls ${ }^{88,107}$, which may in turn be dependent on hippocampal GABAergic function ${ }^{108}$. These findings may form the basis for an understanding of how inner-speech-based frameworks may account for direct control.

Similarly, both direct and indirect control may be accounted for by Bayesian accounts of voicehearing, which attempt to place hallucinations in a common framework with the mechanisms of 
everyday perception. These frameworks conceive of perception as an iterative process of unconscious inference, in which we automatically infer what is around us by combining our sensory input with our prior beliefs about the world ${ }^{109,110}$. This blending of prior beliefs and sensory input is observed readily in many daily situations, from the use of lip-reading cues ${ }^{111}$ and sentence context in understanding speech in auditory noise ${ }^{112}$, to the use of shading for depiction of depth in visual art ${ }^{113}$. Bayesian statistics have been used to construct models describing how this combination of sensory input and prior beliefs takes place ${ }^{114}$. These models have succeeded in predicting performance on a wide range of perceptual tasks ${ }^{115-117}$ as well as the activity of single units and ensembles of neurons in sensory cortices ${ }^{118}$. Within this predictive coding framework, hallucinations may result from overly-weighted perceptual beliefs. In the setting of increased cortical noise (as in psychosis ${ }^{119}$ ), reliance on prior expectations within an auditory system tuned to detect the human voice ${ }^{120}$ may be adaptive.

Converging evidence from several different paradigms has highlighted this over-weighting as being critical in distinguishing participants with and without hallucinations ${ }^{38,121-124}$. Powers and colleagues used a Pavlovian conditioning procedure to produce detection of an auditory target despite its absence, contingent upon the presence of a visual stimulus (i.e., a conditioned auditory hallucination). Performance on the task demonstrated a five-fold increase in reporting conditioned hallucinations in voice-hearers compared to non-voice-hearers, and modeling of behavior on the task revealed that this increase was due to hyper-precise priors in voicehearers ${ }^{122}$. Similarly, Alderson-Day and colleagues showed that non-clinical voice-hearers demonstrate an enhanced ability to recognize sine-wave speech compared to non-voice-hearers, interpreted as an increased ability to use priors in ambiguous perceptual contexts ${ }^{38}$. A related effect was demonstrated by Teufel and colleagues in the visual realm ${ }^{123}$. Lastly, Cassidy and 
colleagues demonstrated that voice-hearers were likely to make more use of prior expectations in judging the duration of an auditory stimulus under different levels of uncertainty ${ }^{125}$.

As with the inner speech hypothesis, attentional reallocation strategies used by those who exhibit indirect control may be explained within the predictive coding framework. In this case, a shift in attention to environmental stimuli may result in an increased precision of sensory evidence ${ }^{126}$, leading to a decrease in the relative weighting of priors and a subsequent decreased propensity to hallucinate.

Direct control may also be explained within the context of the predictive coding framework. Within the perceptual hierarchy, precision of priors at any particular level depends on higherlevel beliefs about the reliability of that information ${ }^{127}$. Thus, higher-level expectations about the relationship between contextual signals and the reliability of perceptual priors may allow for dynamic modulation of the precision of those perceptual priors ${ }^{128}$. Engagement with voices may allow for learning and manipulation of these contextual relationships. Indeed, phenomenological descriptions of the development of direct control abilities focus on the development of a relationship with one's voices in the service of establishing mutually-defined expectations around when and how voices may engage with the voice-hearer ${ }^{28,43,54-56,129}$. Thus, development of direct control over one's voices may result from the influence of learned social and contextual expectations arising from direct engagement with them. If this is true, individuals with better social cognitive abilities may exhibit enhanced direct control compared to those with poor social cognitive skills. Social expectations themselves are learned from one's past social experiences; thus, the use of social expectations to inform precision of perceptual priors may explain some of the known relationships between trauma exposure, locus of control, agency, and ability to control one's hallucinations ${ }^{130}$. Indeed, past trauma has been shown to affect processes related to 
detection of basic auditory stimulus features ${ }^{131}$. These processes also change with affective state $^{132}$. Relatedly, unusual experiences have also recently been linked to absorption and social expectations $^{133}$, providing some evidence that such high-level social expectations can be linked not only to perception in the laboratory, but unusual perceptual experiences as they exist in clinical settings.

An alternative to direct manipulation of prior precision during direct control could be calibration of volatility beliefs regarding the same contextual relationships. A recognition that previouslylearned associations may be changing over time may lead to an adaptive alteration in the precision of priors relative to sensory information, as is seen in some non-treatment-seeking voices-hearers and likely involves structures such as the cerebellum, known to be involved in model-based processing ${ }^{122}$. A more direct pathway toward direct control may also arise from engagement with voices, via more low-level perceptual learning mechanisms. The relationships between direct control, priors, and incoming sensory evidence may perhaps be examined using stimuli for which multiple valid perceptual interpretations may apply. This is the case in bistable or multistable perception, which is susceptible to direct, top-down control ${ }^{134}$ and has known neural correlates ${ }^{135}$. Crucially, these may be similar to those of high-level Bayesian perceptual inference $^{122,136-139}$.

Extension of Bayesian perceptual models toward the inclusion of voluntary action may also provide a new window of opportunity for understanding voluntary control over hallucinations. While traditionally thought of as distinct, informationally-encapsulated processes ${ }^{140}$, perception and action are explicitly related in recent formalized descriptions of perceptual processing. Termed active inference, these models extend the same principles of free-energy minimization underlying the Bayesian models above toward action ${ }^{141}$. Although initially proposed to account 
for the influence of action on perception ${ }^{142}$, recent formulations have proffered valuable extensions toward explanation of diverse phenomena of direct relevance to neuropsychiatry, including action selection ${ }^{143}$, alterations of consciousness ${ }^{144}{ }^{145}$, and psychosis ${ }^{146}$. These models have been extended to provide a compelling formal account of agency and cognitive control $^{147-149}$. Application of mechanisms accounting for agency toward those components involved in basic perceptual inference would likely produce specific hypotheses regarding the development and mechanisms underlying control over hallucinations.

In general, it may be that different sub-populations of voice-hearers exhibit different types of computational deficits. If this is the case, these different subgroups may also vary in their control abilities in a way that reflects their underlying deficits. Lastly, it should be noted that recent advances in neurofeedback training for treatment of auditory hallucinations appear to offer a theory-agnostic demonstration of direct control development ${ }^{150,151}$. In fact, the strategies participants use during neurofeedback sessions appear to be mostly implicit and perceptuallybased (see ${ }^{151}$, Supplement), implying that a perceptual component independent of higher-order cognitive strategy may be isolated from psychosocial factors that influence direct control development. Thus, future work may choose to refine these methods by specifically altering perceptual circuits shown to be involved in the execution of direct control over AVH.

\section{Therapeutic Applications}

Most approaches to enhancing control over hallucinations within established treatment frameworks have focused on the development of active cognitive coping strategies and tools consistent with cognitive-behavioral therapy (CBT)-based treatment. Attention training, a technique aimed at increasing attentional control ${ }^{152}$, was found to increase perceived control over 
AVH in one case study ${ }^{153}$. Chadwick and Birchwood (1994) reported a very low rate of perceived control over voices among a clinical voice-hearing sample ${ }^{71}$, but also described a higher degree of endorsed control after therapy, which correlated with other measures of functional improvement after intervention. They later demonstrated that therapy may result in decreases in beliefs about voice omnipotence, but fails to produce improvement in affect ${ }^{154}$. CBT-based approaches may also result in harm reduction in those with command hallucinations, likely driven by decreased beliefs about the omnipotence of voices ${ }^{155,156}$. Some treatment strategies involve direct interaction with voices, at times using techniques like the Maastricht Approach ${ }^{157}$, which involves examining the meaning and origins of the voices and learning to fit them into a coherent life narrative. Some cases demonstrate the ability of this reframing to produce new, more positive relationships with one's voices ${ }^{129}$.

Although intentional manipulation of explanatory frameworks around voice-hearing experiences and with negotiation with voices may form the basis for new psychotherapies aimed at enhancing agency and control in voice-hearers, an understanding of the computational and neural underpinnings of direct control may lead to a harnessing of these processes for biological interventions. For example, pharmacological, neurofeedback, and rTMS-based interventions may result from an understanding of model parameters and brain regions involved in exerting direct control over voices. Lastly, unlike symptom-focused approaches to treatment aimed at decreasing or eliminating voice-hearing, control-based approaches would reframe treatment toward recovery and development of agency over symptoms in voice-hearers.

Treatment approaches based upon enhancing control over one's voices need not conflict with conventional psychiatric treatment. In fact, these strategies may be some of the most viable options for treatment in individuals who suffer from hallucinations but for whom the risks of 
antipsychotic medications may outweigh the benefits. These populations, including individuals with treatment-resistant $\mathrm{AVH}$ and young people at clinical high risk for psychosis, may be particularly suitable to treatments based upon the findings outlined here.

\section{Conclusions}

The ability to exert some degree of control over aspects of one's auditory hallucinations may be important for long-term outcomes and overall functioning. This observation, while repeated time and again in the literature, will be difficult to translate to new treatments without a more detailed understanding of the varieties of control that may be exerted. Those interested in exploring these abilities may benefit from an initial participant-driven, qualitative approach to the phenomenology of control. This may focus on the spectrum of control abilities as well as on social, demographic, clinical, and perceptual factors contributing to control.

One of the fundamental questions raised by the co-existence of treatment-seeking and nontreatment seeking voice-hearers is that of whether an individual member of one group could have been part of the other had circumstances been different. Or, could an individual currently in one group transition to the other? There is a small amount of evidence to suggest that the development of control abilities may increase functioning: development of control may actually facilitate a change in health status ${ }^{60}$. However, there is clearly a need to study the development of control over AVH in much greater volume and detail. This should be conducted along with indepth characterization of voice-hearing experiences to determine if the difference between clinical and non-clinical voice-hearing populations is one of kind or of circumstance.

There is also clearly a need for a tool to quantify voice-hearers' abilities across the various domains of control. Ideally, such a tool would allow for capture of these abilities at the time of 
appraisal but also at time of initial voice-hearing. Doing so would allow for a staging of control abilities and targeted intervention. Breaking perceived control down into more well-defined abilities may allow for more specific targeting of the cognitive, computational, and neural processes underlying these abilities as well as case-specific staging and intervention based upon the deficits exhibited by each person seeking care. 


\section{Acknowledgements}

This work was supported by a NARSAD Young Investigator Award from the Brain and Behavior Research Foundation, a K23 Career Development Award from the National Institute of Mental Health (K23 MH115252-01A1), a Career Award for Medical Scientists from the Burroughs-Wellcome Fund, and by the Yale University School of Medicine and Department of Psychiatry. Special thanks to Aaron Nidiffer,

Brittany Quagan, Catalina Mougues, Hale Jaeger, Alyson Negreira, Tully Goldrick, Halsey Niles, and Scott Woods for their input. 


\section{References}

$1 \quad$ Esquirol, E. Mental maladies; A treatise on insanity. (Lea and Blanchard, 1845).

2 Falret, J. P. Des Maladies Mentales et des Asiles d'Aliénés, leçons cliniques, etc. (J.-B. Baillière et fils, 1864).

3 Jaspers, K. General psychopathology (trans: Hoenig, J., Hamilton, MW). Manchester. University (1963).

$4 \quad$ Ey, H., Bernard, P. \& Brisset, C. Manuel de psychiatrie. (1972).

5 Telles-Correia, D., Moreira, A. L. \& Goncalves, J. S. Hallucinations and related concepts-their conceptual background. Frontiers in Psychology 6, doi:ARTN 991

10.3389/fpsyg.2015.00991 (2015).

6 Slade, P. D. \& Bentall, R. P. Sensory deception : a scientific analysis of hallucination. (Johns Hopkins University Press, 1988).

7 Aggernaes, A. The experienced reality of hallucinations and other psychological phenomena. An empirical analysis. Acta Psychiatr Scand 48, 220-238 (1972).

$8 \quad$ Bleuler, E. Textbook of psychiatry. (Arno Press, 1976).

9 Bentall, R. \& Slade, P. D. Reliability of a scale measuring disposition towards hallucination: a brief report. Personality and Individual Differences 6, 527-529 (1985).

10 Johns, L. C. Hallucinations in the general population. Current psychiatry reports 7, 162-167 (2005).

11 Johns, L. C. et al. Auditory verbal hallucinations in persons with and without a need for care. Schizophr Bull 40 Suppl 4, S255-264, doi:10.1093/schbul/sbu005 (2014).

12 Laroi, F. \& Van Der Linden, M. Nonclinical participants' reports of hallucinatory experiences. Canadian Journal of Behavioural Science-Revue Canadienne Des Sciences Du Comportement 37, 33-43, doi:DOI 10.1037/h0087243 (2005).

13 Barrett, T. R. \& Etheridge, J. B. Verbal hallucinations in normals, I: People who hear 'voices'. Applied cognitive psychology 6, 379-387 (1992).

14 Allen, P. et al. The prediction of hallucinatory predisposition in non-clinical individuals: Examining the contribution of emotion and reasoning. British Journal of Clinical Psychology 44, 127-132 (2005).

15 Aleman, A., Böcker, K. B. \& De Haan, E. H. Hallucinatory predisposition and vividness of auditory imagery: self-report and behavioral indices. Perceptual and motor skills 93, 268-274 (2001).

16 Eaton, W. W., Romanoski, A., Anthony, J. C. \& Nestadt, G. Screening for psychosis in the general population with a self-report interview. J Nerv Ment Dis 179, 689-693 (1991).

17 Johns, L. C. et al. Prevalence and correlates of self-reported psychotic symptoms in the British population. British Journal of Psychiatry 185, 298-305, doi:DOI 10.1192/bjp.185.4.298 (2004).

18 Sidgwick, H., Johnson, A., Myers, F. W. H., Podmore, F. \& Sidgwick, E. M. Report on the Census on Hallucinations. Proceedings of the Society of Psychical Research X, 25-422 (1894).

19 Tien, A. Y. Distributions of Hallucinations in the Population. Social Psychiatry and Psychiatric Epidemiology 26, 287-292, doi:Doi 10.1007/Bf00789221 (1991).

20 Beavan, V., Read, J. \& Cartwright, C. The prevalence of voice-hearers in the general population: a literature review. J Ment Health 20, 281-292, doi:10.3109/09638237.2011.562262 (2011).

21 Sommer, I. E. et al. Healthy individuals with auditory verbal hallucinations; who are they? Psychiatric assessments of a selected sample of 103 subjects. Schizophr Bull 36, 633-641, doi:10.1093/schbul/sbn130 (2010).

22 Linscott, R. J. \& van Os, J. An updated and conservative systematic review and meta-analysis of epidemiological evidence on psychotic experiences in children and adults: on the pathway from 
proneness to persistence to dimensional expression across mental disorders. Psychol Med 43, 1133-1149, doi:10.1017/S0033291712001626 (2013).

23 Baumeister, D., Sedgwick, O., Howes, O. \& Peters, E. Auditory verbal hallucinations and continuum models of psychosis: A systematic review of the healthy voice-hearer literature. Clin Psychol Rev 51, 125-141, doi:10.1016/j.cpr.2016.10.010 (2017).

24 Murphy, J. M. Psychiatric labeling in cross-cultural perspective. Science 191, 1019-1028 (1976).

25 Linscott, R. J. \& van Os, J. Systematic reviews of categorical versus continuum models in psychosis: evidence for discontinuous subpopulations underlying a psychometric continuum. Implications for DSM-V, DSM-VI, and DSM-VII. Annual review of clinical psychology 6, 391-419 (2010).

26 Daalman, K. et al. The same or different? A phenomenological comparison of auditory verbal hallucinations in healthy and psychotic individuals. J clin Psychiatry 72, 320-325 (2011).

27 Hill, K., Varese, F., Jackson, M. \& Linden, D. E. The relationship between metacognitive beliefs, auditory hallucinations, and hallucination-related distress in clinical and non-clinical voicehearers. British Journal of Clinical Psychology 51, 434-447 (2012).

28 Powers, A. R., 3rd, Kelley, M. S. \& Corlett, P. R. Varieties of Voice-Hearing: Psychics and the Psychosis Continuum. Schizophr Bull 43, 84-98, doi:10.1093/schbul/sbw133 (2017).

29 Larøi, F. How do auditory verbal hallucinations in patients differ from those in non-patients? Frontiers in human neuroscience 6, 25 (2012).

30 Baumeister, D., Sedgwick, O., Howes, O. \& Peters, E. Auditory verbal hallucinations and continuum models of psychosis: a systematic review of the healthy voice-hearer literature. Clinical psychology review 51, 125-141 (2017).

31 de Leede-Smith, S. \& Barkus, E. A comprehensive review of auditory verbal hallucinations: lifetime prevalence, correlates and mechanisms in healthy and clinical individuals. Front Hum Neurosci 7, 367, doi:10.3389/fnhum.2013.00367 (2013).

32 Daalman, K., Verkooijen, S., Derks, E. M., Aleman, A. \& Sommer, I. E. The influence of semantic top-down processing in auditory verbal hallucinations. Schizophr Res 139, 82-86, doi:10.1016/j.schres.2012.06.005 (2012).

33 Daalman, K., Sommer, I. E., Derks, E. M. \& Peters, E. R. Cognitive biases and auditory verbal hallucinations in healthy and clinical individuals. Psychol Med 43, 2339-2347, doi:10.1017/S0033291713000275 (2013).

34 de Weijer, A. D. et al. Aberrations in the arcuate fasciculus are associated with auditory verbal hallucinations in psychotic and in non-psychotic individuals. Hum Brain Mapp 34, 626-634, doi:10.1002/hbm.21463 (2013).

35 Diederen, K. M., van Lutterveld, R. \& Sommer, I. E. Neuroimaging of voice hearing in nonpsychotic individuals: a mini review. Front Hum Neurosci 6, 111, doi:10.3389/fnhum.2012.00111 (2012).

36 Diederen, K. M. et al. Decreased language lateralization is characteristic of psychosis, not auditory hallucinations. Brain 133, 3734-3744, doi:10.1093/brain/awq313 (2010).

37 Slotema, C. W. et al. Auditory verbal hallucinations in patients with borderline personality disorder are similar to those in schizophrenia. Psychol Med 42, 1873-1878, doi:10.1017/S0033291712000165 (2012).

38 Alderson-Day, B. et al. Distinct processing of ambiguous speech in people with non-clinical auditory verbal hallucinations. Brain 140, 2475-2489, doi:10.1093/brain/awx206 (2017).

39 Andrew, E. M., Gray, N. S. \& Snowden, R. J. The relationship between trauma and beliefs about hearing voices: a study of psychiatric and non-psychiatric voice hearers. Psychol Med 38, 14091417, doi:10.1017/s003329170700253x (2008). 
Daalman, K. et al. Auditory verbal hallucinations and cognitive functioning in healthy individuals. Schizophr Res 132, 203-207, doi:10.1016/j.schres.2011.07.013 (2011).

41 Daalman, K. et al. The same or different? A phenomenological comparison of auditory verbal hallucinations in healthy and psychotic individuals. J Clin Psychiatry 72, 320-325, doi:10.4088/JCP.09m05797yel (2011).

42 Honig, A. et al. Auditory hallucinations: a comparison between patients and nonpatients. The Journal of nervous and mental disease 186, 646-651 (1998).

43 Roxburgh, E. C. \& Roe, C. A. Reframing voices and visions using a spiritual model. An interpretative phenomenological analysis of anomalous experiences in mediumship. Mental Health, Religion \& Culture 17, 641-653 (2014).

44 Garety, P. A., Kuipers, E., Fowler, D., Freeman, D. \& Bebbington, P. E. A cognitive model of the positive symptoms of psychosis. Psychol Med 31, 189-195 (2001).

45 Alderson-Day, B. et al. Distinct processing of ambiguous speech in people with non-clinical auditory verbal hallucinations. Brain 140, 2475-2489, doi:10.1093/brain/awx206 (2017). Luhrmann, T. M. et al. Beyond Trauma: A Multiple Pathways Approach to Auditory Hallucinations in Clinical and Nonclinical Populations. Schizophrenia Bulletin 45, S24-S31, doi:10.1093/schbul/sby110 (2019).

47 Falloon, I. R. \& Talbot, R. E. Persistent auditory hallucinations: coping mechanisms and implications for management. Psychol Med 11, 329-339 (1981).

48 Bentall, R. P., Haddock, G. \& Slade, P. D. Cognitive behavior therapy for persistent auditory hallucinations: From theory to therapy. Behavior Therapy 25, 51-66 (1994).

49 Roxburgh, E. C. \& Roe, C. A. A survey of dissociation, boundary-thinness, and psychological wellbeing in spiritualist mental mediumship. Journal of Parapsychology 75, 279-299 (2011). Haddock, G., McCarron, J., Tarrier, N. \& Faragher, E. B. Scales to measure dimensions of hallucinations and delusions: the psychotic symptom rating scales (PSYRATS). Psychol Med 29, 879-889 (1999).

51 Paulik, G., Badcock, J. C. \& Maybery, M. T. Dissociating the components of inhibitory control involved in predisposition to hallucinations. Cogn Neuropsychiatry 13, 33-46, doi:10.1080/13546800701775683 (2008).

52 Taylor, G. \& Murray, C. A qualitative investigation into non-clinical voice hearing: what factors may protect against distress? Mental Health, Religion \& Culture 15, 373-388 (2012).

53 Alderson-Day, B. et al. Intentional inhibition but not source memory is related to hallucinationproneness and intrusive thoughts in a university sample. Cortex 113, 267-278, doi:10.1016/j.cortex.2018.12.020 (2019).

54 Romme, M. A., Honig, A., Noorthoorn, E. O. \& Escher, A. D. Coping with hearing voices: an emancipatory approach. Br J Psychiatry 161, 99-103 (1992).

55 Romme, M. \& Escher, S. Accepting voices. (MIND Publications, 1993).

56 Romme, M. \& Escher, S. Making Sense of Voices: The Mental Health Professional's Guide to Working with Voice-hearers. (Mind Publications, 2000).

57 Haddock, G., McCarron, J., Tarrier, N. \& Faragher, E. Scales to measure dimensions of hallucinations and delusions: the psychotic symptom rating scales (PSYRATS). Psychological medicine 29, 879-889 (1999).

58 Birchwood, M., Mason, R., MacMillan, F. \& Healy, J. Depression, demoralization and control over psychotic illness: a comparison of depressed and non-depressed patients with a chronic psychosis. Psychol Med 23, 387-395 (1993).

59 Romme, M. A. \& Escher, A. D. Hearing voices. Schizophr Bull 15, 209-216 (1989).

60 Luhrmann, T. Living with voices. The American Scholar 81, 48-60 (2012). 
Rotter, J. B. Generalized expectancies for internal versus external control of reinforcement. Psychological monographs: General and applied 80, 1 (1966).

62 Harrow, M., Hansford, B. G. \& Astrachan-Fletcher, E. B. Locus of control: Relation to schizophrenia, to recovery, and to depression and psychosis-A 15-year longitudinal study. Psychiatry research 168, 186-192 (2009).

63 Mirsky, A. F., Kugelmass, S., Ingraham, L. J., Frenkel, E. \& Nathan, M. Overview and summary: twenty-five-year followup of high-risk children. Schizophrenia Bulletin 21, 227-239 (1995). Jackson, L. J., Hayward, M. \& Cooke, A. Developing positive relationships with voices: a preliminary Grounded Theory. The International journal of social psychiatry 57, 487-495, doi:10.1177/0020764010368624 (2011).

65 Smith, B. et al. Emotion and psychosis: links between depression, self-esteem, negative schematic beliefs and delusions and hallucinations. Schizophrenia research 86, 181-188 (2006). Sorrell, E., Hayward, M. \& Meddings, S. Interpersonal processes and hearing voices: a study of the association between relating to voices and distress in clinical and non-clinical hearers. Behavioural and Cognitive Psychotherapy 38, 127-140 (2010).

67 Benassi, V. A., Sweeney, P. D. \& Dufour, C. L. Is there a relation between locus of control orientation and depression? Journal of abnormal psychology 97, 357 (1988). Chung, M. C., Preveza, E., Papandreou, K. \& Prevezas, N. Locus of control among spinal cord injury patients with different levels of posttraumatic stress disorder. Psychiatry research 152, 253-260 (2007). Daalman, K. et al. Childhood trauma and auditory verbal hallucinations. Psychological Medicine 42, 2475-2484 (2012).

70 Jones, S. R. \& Fernyhough, C. The roles of locus of control and self-esteem in hallucination-and delusion-proneness in a non-clinical sample. Personality and Individual Differences 43, 10871097 (2007).

71 Chadwick, P. \& Birchwood, M. The omnipotence of voices. A cognitive approach to auditory hallucinations. Br J Psychiatry 164, 190-201 (1994).

72 Peters, E. R., Williams, S. L., Cooke, M. A. \& Kuipers, E. It's not what you hear, it's the way you think about it: appraisals as determinants of affect and behaviour in voice hearers. Psychol Med 42, 1507-1514, doi:10.1017/S0033291711002650 (2012).

73 Peters, E., Williams, S., Cooke, M. \& Kuipers, E. It's not what you hear, it's the way you think about it: appraisals as determinants of affect and behaviour in voice hearers. Psychological Medicine 42, 1507-1514 (2012).

74 Singh, G., Sharan, P. \& Kulhara, P. Role of coping strategies and attitudes in mediating distress due to hallucinations in schizophrenia. Psychiatry and Clinical Neurosciences 57, 517-522 (2003).

75 Goldstone, E., Farhall, J. \& Ong, B. Modelling the emergence of hallucinations: early acquired vulnerabilities, proximal life stressors and maladaptive psychological processes. Social psychiatry and psychiatric epidemiology 47, 1367-1380 (2012).

76 Jackson, L. J., Hayward, M. \& Cooke, A. Developing positive relationships with voices: A preliminary grounded theory. International Journal of Social Psychiatry 57, 487-495 (2011).

77 Hayward, M. Interpersonal relating and voice hearing: to what extent does relating to the voice reflect social relating? Psychology and Psychotherapy: Theory, Research and Practice 76, 369383 (2003).

78 Birchwood, M., Meaden, A., Trower, P., Gilbert, P. \& Plaistow, J. The power and omnipotence of voices: subordination and entrapment by voices and significant others. Psychol Med 30, 337-344 (2000).

79 Jones, N. et al. "Did I push myself over the edge?": Complications of agency in psychosis onset and development. Psychosis 8, 324-335 (2016). 
Hoffman, R. E. Auditory/Verbal hallucinations, speech perception neurocircuitry, and the social deafferentation hypothesis. Clin EEG Neurosci 39, 87-90 (2008).

81 Badcock, J. C. The cognitive neuropsychology of auditory hallucinations: a parallel auditory pathways framework. Schizophr Bull 36, 576-584, doi:10.1093/schbul/sbn128 (2010).

82 Vaughan, S. \& Fowler, D. The distress experienced by voice hearers is associated with the perceived relationship between the voice hearer and the voice. British Journal of Clinical Psychology 43, 143-153 (2004).

83 Bucci, S. et al. Predicting compliance with command hallucinations: anger, impulsivity and appraisals of voices' power and intent. Schizophrenia research 147, 163-168 (2013).

84 Lawrence, C., Jones, J. \& Cooper, M. Hearing voices in a non-psychiatric population. Behavioural and Cognitive Psychotherapy 38, 363-373 (2010).

85 Brett, C., Johns, L., Peters, E. \& McGuire, P. The role of metacognitive beliefs in determining the impact of anomalous experiences: a comparison of help-seeking and non-help-seeking groups of people experiencing psychotic-like anomalies. Psychological medicine 39, 939-950 (2009). Cartwright-Hatton, S. \& Wells, A. Beliefs about worry and intrusions: The Meta-Cognitions Questionnaire and its correlates. Journal of anxiety disorders 11, 279-296 (1997).

87 Hill, K., Varese, F., Jackson, M. \& Linden, D. E. The relationship between metacognitive beliefs, auditory hallucinations, and hallucination-related distress in clinical and non-clinical voicehearers. Br J Clin Psychol 51, 434-447, doi:10.1111/j.2044-8260.2012.02039.x (2012). Waters, F. A., Badcock, J. C., Maybery, M. T. \& Michie, P. T. Inhibition in schizophrenia: association with auditory hallucinations. Schizophr Res 62, 275-280 (2003). Jardri, R. et al. Are Hallucinations Due to an Imbalance Between Excitatory and Inhibitory Influences on the Brain? Schizophrenia Bulletin 42, 1124-1134, doi:10.1093/schbul/sbw075 (2016).

90 Linden, D. E. et al. The brain's voices: comparing nonclinical auditory hallucinations and imagery. Cerebral Cortex 21, 330-337 (2010).

91 Luhrmann, T. M. Hallucinations and sensory overrides. Annual Review of Anthropology 40, 71-85 (2011).

92 Luhrmann, T. M., Padmavati, R., Tharoor, H. \& Osei, A. Differences in voice-hearing experiences of people with psychosis in the USA, India and Ghana: interview-based study. The British Journal of Psychiatry 206, 41-44 (2015).

93 Wolpert, D. M., Ghahramani, Z. \& Jordan, M. I. An internal model for sensorimotor integration. Science 269, 1880-1882 (1995).

94 Frith, C. The neural basis of hallucinations and delusions. C R Biol 328, 169-175 (2005).

95 Ford, J. M. \& Mathalon, D. H. Corollary discharge dysfunction in schizophrenia: can it explain auditory hallucinations? Int J Psychophysio/ 58, 179-189, doi:10.1016/j.ijpsycho.2005.01.014 (2005).

96 Shergill, S. S., Samson, G., Bays, P. M., Frith, C. D. \& Wolpert, D. M. Evidence for sensory prediction deficits in schizophrenia. Am J Psychiatry 162, 2384-2386, doi:10.1176/appi.ajp.162.12.2384 (2005).

97 Lindner, A., Thier, P., Kircher, T. T., Haarmeier, T. \& Leube, D. T. Disorders of agency in schizophrenia correlate with an inability to compensate for the sensory consequences of actions. Curr Biol 15, 1119-1124, doi:10.1016/j.cub.2005.05.049 (2005).

98 Spering, M., Dias, E. C., Sanchez, J. L., Schutz, A. C. \& Javitt, D. C. Efference copy failure during smooth pursuit eye movements in schizophrenia. J Neurosci 33, 11779-11787, doi:10.1523/JNEUROSCI.0578-13.2013 (2013).

99 Thakkar, K. N., Schall, J. D., Heckers, S. \& Park, S. Disrupted Saccadic Corollary Discharge in Schizophrenia. J Neurosci 35, 9935-9945, doi:10.1523/JNEUROSCI.0473-15.2015 (2015). 
100 Ford, J. M., Roach, B. J., Faustman, W. O. \& Mathalon, D. H. Synch before you speak: auditory hallucinations in schizophrenia. Am J Psychiatry 164, 458-466, doi:10.1176/ajp.2007.164.3.458 (2007).

101 Ford, J. M. et al. Cortical responsiveness during inner speech in schizophrenia: an event-related potential study. Am J Psychiatry 158, 1914-1916, doi:10.1176/appi.ajp.158.11.1914 (2001).

102 Ford, J. M. et al. Neurophysiological evidence of corollary discharge dysfunction in schizophrenia. Am J Psychiatry 158, 2069-2071, doi:10.1176/appi.ajp.158.12.2069 (2001).

103 Heinks-Maldonado, T. H. et al. Relationship of imprecise corollary discharge in schizophrenia to auditory hallucinations. Arch Gen Psychiatry 64, 286-296, doi:10.1001/archpsyc.64.3.286 (2007).

104 Bansal, S., Ford, J. M. \& Spering, M. The function and failure of sensory predictions. Ann N $Y$ Acad Sci, doi:10.1111/nyas.13686 (2018).

105 Morrison, A. P. \& Baker, C. A. Intrusive thoughts and auditory hallucinations: a comparative study of intrusions in psychosis. Behaviour research and therapy 38, 1097-1106 (2000).

106 Hartley, S., Haddock, G., Vasconcelos e Sa, D., Emsley, R. \& Barrowclough, C. The influence of thought control on the experience of persecutory delusions and auditory hallucinations in daily life. Behav Res Ther 65, 1-4, doi:10.1016/j.brat.2014.12.002 (2015).

107 Badcock, J. C., Waters, F. A., Maybery, M. T. \& Michie, P. T. Auditory hallucinations: failure to inhibit irrelevant memories. Cognitive neuropsychiatry 10, 125-136, doi:10.1080/13546800344000363 (2005).

108 Schmitz, T. W., Correia, M. M., Ferreira, C. S., Prescot, A. P. \& Anderson, M. C. Hippocampal GABA enables inhibitory control over unwanted thoughts. Nat Commun 8, 1311, doi:10.1038/s41467-017-00956-z (2017).

109 Friston, K. Hierarchical models in the brain. PLoS computational biology 4, e1000211, doi:10.1371/journal.pcbi.1000211 (2008).

110 Friston, $\mathrm{K}$. The free-energy principle: a rough guide to the brain? Trends in cognitive sciences 13, 293-301, doi:10.1016/j.tics.2009.04.005 (2009).

111 Noppeney, U., Josephs, O., Hocking, J., Price, C. J. \& Friston, K. J. The effect of prior visual information on recognition of speech and sounds. Cerebral cortex 18, 598-609, doi:10.1093/cercor/bhm091 (2008).

112 Lau, E. F., Phillips, C. \& Poeppel, D. A cortical network for semantics: (de)constructing the N400. Nature reviews. Neuroscience 9, 920-933, doi:10.1038/nrn2532 (2008).

113 Lee, T. S. \& Mumford, D. Hierarchical Bayesian inference in the visual cortex. Journal of the Optical Society of America. A, Optics, image science, and vision 20, 1434-1448 (2003).

114 Friston, K. \& Kiebel, S. Predictive coding under the free-energy principle. Philosophical transactions of the Royal Society of London. Series B, Biological sciences 364, 1211-1221, doi:10.1098/rstb.2008.0300 (2009).

115 Petzschner, F. H., Glasauer, S. \& Stephan, K. E. A Bayesian perspective on magnitude estimation. Trends in cognitive sciences, doi:10.1016/j.tics.2015.03.002 (2015).

116 Dayan, P. A hierarchical model of binocular rivalry. Neural computation 10, 1119-1135 (1998).

117 Schellekens, W., van Wezel, R. J., Petridou, N., Ramsey, N. F. \& Raemaekers, M. Predictive coding for motion stimuli in human early visual cortex. Brain structure \& function, doi:10.1007/s00429-014-0942-2 (2014).

118 Baldeweg, T. Repetition effects to sounds: evidence for predictive coding in the auditory system. Trends in cognitive sciences 10, 93-94, doi:10.1016/j.tics.2006.01.010 (2006).

119 Winterer, G. \& Weinberger, D. R. Genes, dopamine and cortical signal-to-noise ratio in schizophrenia. Trends Neurosci 27, 683-690, doi:10.1016/j.tins.2004.08.002 (2004). 
120 Moerel, M., De Martino, F. \& Formisano, E. Processing of natural sounds in human auditory cortex: tonotopy, spectral tuning, and relation to voice sensitivity. J Neurosci 32, 14205-14216, doi:10.1523/JNEUROSCI.1388-12.2012 (2012).

121 Corlett, P. R. et al. Hallucinations and Strong Priors. Trends Cogn Sci 23, 114-127, doi:10.1016/j.tics.2018.12.001 (2019).

122 Powers, A. R., Mathys, C. \& Corlett, P. R. Pavlovian conditioning-induced hallucinations result from overweighting of perceptual priors. Science 357, 596-600, doi:10.1126/science.aan3458 (2017).

123 Teufel, C. et al. Shift toward prior knowledge confers a perceptual advantage in early psychosis and psychosis-prone healthy individuals. Proc Natl Acad Sci U S A, doi:10.1073/pnas.1503916112 (2015).

124 Horga, G., Schatz, K. C., Abi-Dargham, A. \& Peterson, B. S. Deficits in predictive coding underlie hallucinations in schizophrenia. J Neurosci 34, 8072-8082, doi:10.1523/JNEUROSCI.0200-14.2014 (2014).

125 Cassidy, C. M. et al. A Perceptual Inference Mechanism for Hallucinations Linked to Striatal Dopamine. Curr Biol 28, 503-514 e504, doi:10.1016/j.cub.2017.12.059 (2018).

126 Feldman, H. \& Friston, K. J. Attention, uncertainty, and free-energy. Front Hum Neurosci 4, 215, doi:10.3389/fnhum.2010.00215 (2010).

127 Mathys, C., Daunizeau, J., Friston, K. J. \& Stephan, K. E. A bayesian foundation for individual learning under uncertainty. Front Hum Neurosci 5, 39, doi:10.3389/fnhum.2011.00039 (2011).

128 Hohwy, J. Priors in perception: Top-down modulation, Bayesian perceptual learning rate, and prediction error minimization. Conscious Cogn 47, 75-85, doi:10.1016/j.concog.2016.09.004 (2017).

129 Knols, M. \& Corstens, D. Tuning in: a story by a patient and a therapist about making sense of voices. Mental health today (Brighton, England), 28-32 (2011).

130 Friston, K., Breakspear, M. \& Deco, G. Perception and self-organized instability. Front Comput Neurosci 6, 44, doi:10.3389/fncom.2012.00044 (2012).

131 Bangel, K. A., van Buschbach, S., Smit, D. J. A., Mazaheri, A. \& Olff, M. Aberrant brain response after auditory deviance in PTSD compared to trauma controls: An EEG study. Sci Rep 7, 16596, doi:10.1038/s41598-017-16669-8 (2017).

132 Pinheiro, A. P., Barros, C., Dias, M. \& Niznikiewicz, M. Does emotion change auditory prediction and deviance detection? Biological Psychology 127, 123-133, doi:10.1016/j.biopsycho.2017.05.007 (2017).

133 Maij, D. L. R. \& van Elk, M. Getting absorbed in experimentally induced extraordinary experiences: Effects of placebo brain stimulation on agency detection. Consciousness and Cognition 66, 1-16, doi:10.1016/j.concog.2018.09.010 (2018).

134 Meng, M. \& Tong, F. Can attention selectively bias bistable perception? Differences between binocular rivalry and ambiguous figures. Journal of Vision 4, 539-551, doi:10.1167/4.7.2 (2004).

135 Tong, F., Wong, A., Meng, M. \& McKeeff, T. J. Brain areas involved in attentional control and perception of ambiguous figures. Journal of Vision 2, 677-677 (2002).

136 de Graaf, T. A., de Jong, M. C., Goebel, R., van Ee, R. \& Sack, A. T. On the Functional Relevance of Frontal Cortex for Passive and Voluntarily Controlled Bistable Vision. Cerebral Cortex 21, 23222331, doi:10.1093/cercor/bhr015 (2011).

137 Vernet, M., Brem, A.-K., Farzan, F. \& Pascual-Leone, A. Synchronous and opposite roles of the parietal and prefrontal cortices in bistable perception: a double-coil TMS-EEG study. Cortex 64, 78-88 (2015). 
138 Weilnhammer, V., Stuke, H., Hesselmann, G., Sterzer, P. \& Schmack, K. A predictive coding account of bistable perception - a model-based fMRI study. PLoS Comput Biol 13, e1005536, doi:10.1371/journal.pcbi.1005536 (2017).

139 Weilnhammer, V. A., Ludwig, K., Hesselmann, G. \& Sterzer, P. Frontoparietal cortex mediates perceptual transitions in bistable perception. J Neurosci 33, 16009-16015, doi:10.1523/JNEUROSCI.1418-13.2013 (2013).

140 Fodor, J. A. The modularity of mind : an essay on faculty psychology. (MIT Press, 1983).

141 Friston, K., Mattout, J. \& Kilner, J. Action understanding and active inference. Biol Cybern 104, 137-160, doi:10.1007/s00422-011-0424-z (2011).

142 Brown, H., Adams, R. A., Parees, I., Edwards, M. \& Friston, K. Active inference, sensory attenuation and illusions. Cogn Process 14, 411-427, doi:10.1007/s10339-013-0571-3 (2013).

143 Friston, K. J. et al. Dopamine, affordance and active inference. PLoS Comput Biol 8, e1002327, doi:10.1371/journal.pcbi.1002327 (2012).

144 Rudrauf, D. et al. A mathematical model of embodied consciousness. J Theor Biol 428, 106-131, doi:10.1016/j.jtbi.2017.05.032 (2017).

145 Williford, K., Bennequin, D., Friston, K. \& Rudrauf, D. The Projective Consciousness Model and Phenomenal Selfhood. Front Psychol 9, 2571, doi:10.3389/fpsyg.2018.02571 (2018).

146 Adams, R. A., Perrinet, L. U. \& Friston, K. Smooth pursuit and visual occlusion: active inference and oculomotor control in schizophrenia. PLoS One 7, e47502, doi:10.1371/journal.pone.0047502 (2012).

147 Friston, K. Active inference and agency. Cogn Neurosci 5, 119-121, doi:10.1080/17588928.2014.905517 (2014).

148 Friston, K. et al. The anatomy of choice: active inference and agency. Front Hum Neurosci 7, 598, doi:10.3389/fnhum.2013.00598 (2013).

149 Pezzulo, G. An Active Inference view of cognitive control. Front Psychol 3, 478, doi:10.3389/fpsyg.2012.00478 (2012).

150 Orlov, N. D. et al. Real-time fMRI neurofeedback to down-regulate superior temporal gyrus activity in patients with schizophrenia and auditory hallucinations: a proof-of-concept study. Transl Psychiatry 8, 46, doi:10.1038/s41398-017-0067-5 (2018).

151 Fovet, T. et al. Translating Neurocognitive Models of Auditory-Verbal Hallucinations into Therapy: Using Real-time fMRI-Neurofeedback to Treat Voices. Front Psychiatry 7, 103, doi:10.3389/fpsyt.2016.00103 (2016).

152 Wells, A. Panic disorder in association with relaxation induced anxiety: An attentional training approach to treatment. Behavior Therapy 21, 273-280 (1990).

153 Valmaggia, L. R., Bouman, T. K. \& Schuurman, L. Attention training with auditory hallucinations: A case study. Cognitive and Behavioral Practice 14, 127-133 (2007).

154 Chadwick, P., Sambrooke, S., Rasch, S. \& Davies, E. Challenging the omnipotence of voices: group cognitive behavior therapy for voices. Behav Res Ther 38, 993-1003 (2000).

155 Hutton, P., Morrison, A. P. \& Taylor, H. Brief cognitive behavioural therapy for hallucinations: can it help people who decide not to take antipsychotic medication? A case report. Behav Cogn Psychother 40, 111-116, doi:10.1017/S135246581100035X (2012).

156 Trower, P. et al. Cognitive therapy for command hallucinations: randomised controlled trial. The British Journal of Psychiatry 184, 312-320 (2004).

157 Corstens, D., Escher, S. \& Romme, M. Accepting and working with voices: The Maastricht approach. Psychosis, trauma and dissociation: Emerging perspectives on severe psychopathology, 319-332 (2008). 


\section{Figure Legends}

Figure 1. Spectrum of Control over Hallucinations. Phenomenological descriptions of degree of control over hallucinations in voice-hearing populations include a large spectrum of abilities. Some may be classed as "indirect control" abilities, which take advantage of the relationships that exist between domains that may be manipulated (like attention and overall sense of wellness and control over one's life) and the potential for voices to impact the voicehearer negatively. Others may be described as "direct control" abilities, which use various techniques to directly influence voices' onset and offset. These abilities have been described in several different populations and likely rely on different cognitive abilities and computational and neural architectures. All appear to be amenable to purposeful development. We argue that all of these abilities are likely captured by commonly-used clinical rating scales. However, a fuller understanding of overall control's component parts may be important for development of novel treatment strategies based on their cognitive or neural underpinnings. 


\begin{tabular}{|c|c|c|c|c|}
\hline Authors & Year & Study Design / Type & Participants & Type of Control Described \\
\hline $\begin{array}{l}\text { Powers, Kelley, } \\
\text { Corlett }\end{array}$ & 2017 & $\begin{array}{l}\text { Quantitative: } \\
\text { Questionnaire-based } \\
\text { +Qualitative: Semi- } \\
\text { structured Interview }\end{array}$ & $\begin{array}{l}\mathrm{N}=67 \text { Participants } \\
\text { with psychotic } \\
\text { disorders, with and } \\
\text { without AVH and } \\
\text { participants } \\
\text { without psychotic } \\
\text { disorders with and } \\
\text { without AVH. }\end{array}$ & $\begin{array}{l}\text { Direct Control: Clairaudient } \\
\text { psychics able to control the onset } \\
\text { and offset of voices. }\end{array}$ \\
\hline Roxburgh \& Roe & 2014 & Qualitative: Interviews & $\begin{array}{l}\mathrm{N}=6 \text { Spiritualist } \\
\text { mediums }\end{array}$ & $\begin{array}{l}\text { Direct Control: Mediums describe } \\
\text { ability to "prevent or assist" } \\
\text { communication }\end{array}$ \\
\hline Taylor \& Murray & 2012 & Qualitative: Interview & $\mathrm{N}=6$ mediums & $\begin{array}{l}\text { Direct Control: Mediums are able } \\
\text { to choose when to engage with } \\
\text { spirits. }\end{array}$ \\
\hline $\begin{array}{l}\text { Jackson, Hayward, } \\
\text { Cooke }\end{array}$ & & Qualitative: Interview & $\begin{array}{l}\mathrm{N}=12 \text { voice- } \\
\text { hearers both with } \\
\text { and without a } \\
\text { psychiatric } \\
\text { diagnosis. }\end{array}$ & $\begin{array}{l}\text { Direct Control: Asserting } \\
\text { boundaries through use of sprit } \\
\text { guides, visualization, used to } \\
\text { increase control. }\end{array}$ \\
\hline $\begin{array}{l}\text { Thorstens \& } \\
\text { Knols }\end{array}$ & 2011 & $\begin{array}{l}\text { Qualitative: Case study } \\
\text { of treatment with } \\
\text { Maastricht Approach }\end{array}$ & $\begin{array}{l}\mathrm{N}=1 \text { individual } \\
\text { with } \mathrm{AVH}\end{array}$ & $\begin{array}{l}\text { Direct Control: Therapy aimed at } \\
\text { helping patient understand } \\
\text { meaning of voices helped him gain } \\
\text { control over them. }\end{array}$ \\
\hline $\begin{array}{l}\text { Chadwick \& } \\
\text { Birchwood }\end{array}$ & 1994 & Qualitative: Interview & $\begin{array}{l}\mathrm{N}=25 \text { participants } \\
\text { with schizophrenia }\end{array}$ & $\begin{array}{l}\text { Direct Control: Some participants } \\
\text { able to control onset or offset of } \\
\text { voices. }\end{array}$ \\
\hline $\begin{array}{l}\text { Hutton, Morrison, } \\
\text { Taylor }\end{array}$ & 2012 & $\begin{array}{l}\text { Qualitative: Case } \\
\text { Study. }\end{array}$ & $\begin{array}{l}\mathrm{N}=1 \text { individual } \\
\text { with distressing } \\
\text { and dominating } \\
\text { AVH. }\end{array}$ & $\begin{array}{l}\text { Direct/Indirect Control: } \mathrm{CBT} \\
\text { associated with decrease in } \\
\text { dominance of AVH, ultimate } \\
\text { disappearance of AVH }\end{array}$ \\
\hline Gottlieb et al. & 2013 & $\begin{array}{l}\text { Quantitative: } \\
\text { Questionnaire-based } \\
\text { (PSYRATS) }\end{array}$ & $\begin{array}{l}\mathrm{N}=21 \text { individuals } \\
\text { with schizophrenia } \\
\text { spectrum disorder, } \\
\text { AVH }\end{array}$ & $\begin{array}{l}\text { Indirect Control: Greater } \\
\text { perceived control over voices after } \\
\text { completing CBTp. }\end{array}$ \\
\hline Falloon \& Talbott & 1981 & Qualitative: Interview & $\begin{array}{l}\mathrm{N}=40 \\
\text { schizophrenia } \\
\text { inpatients }\end{array}$ & $\begin{array}{l}\text { Indirect Control: Some voice } \\
\text { hearers can use cognitive } \\
\text { strategies to manage voices. }\end{array}$ \\
\hline Bentall & 1994 & $\begin{array}{l}\text { Patients assessed } \\
\text { before and after } \\
\text { receiving focusing } \\
\text { therapy. }\end{array}$ & $\begin{array}{l}\mathrm{N}=6 \text { Patients with } \\
\text { schizophrenia }\end{array}$ & $\begin{array}{l}\text { Indirect Control: Focusing therapy } \\
\text { can be used to manage voices. }\end{array}$ \\
\hline Peters et al. & 2011 & $\begin{array}{l}\text { Quantitative: } \\
\text { Questionnaire-based. }\end{array}$ & $\begin{array}{l}\mathrm{N}=46 \text { participants } \\
\text { at an outpatient } \\
\text { psychosis clinic }\end{array}$ & $\begin{array}{l}\text { General Control: resistance to } \\
\text { voices correlated with higher } \\
\text { levels of perceived omnipotence } \\
\text { of voices and greater voice related } \\
\text { distress. }\end{array}$ \\
\hline Singh, Sharan, & 2003 & Quantitative: & $\mathrm{N}=75$ & General Control: \\
\hline
\end{tabular}




\begin{tabular}{|l|l|l|l|l|}
\hline Kulhara & & Questionnaire based. & $\begin{array}{l}\text { schizophrenia } \\
\text { patients }\end{array}$ & $\begin{array}{l}\text { attempts to resist or block voices } \\
\text { led to greater perceived } \\
\text { intrusiveness }\end{array}$ \\
\hline Chadwick et al. & 2000 & $\begin{array}{l}\text { Quantitative: } \\
\text { Questionnaire-based. }\end{array}$ & $\begin{array}{l}\text { N=18 patients } \\
\text { experiencing drug- } \\
\text { resistant, } \\
\text { distressing AVH }\end{array}$ & $\begin{array}{l}\text { General Control: CBT led to } \\
\text { reduction in appraisals of voices as } \\
\text { omnipotent }\end{array}$ \\
\hline Honig et al. & 1998 & $\begin{array}{l}\text { Quantitative: Semi- } \\
\text { structured Interview }\end{array}$ & $\begin{array}{l}\text { N=48 participants } \\
\text { with AVH }\end{array}$ & $\begin{array}{l}\text { Perceived / Rated Control }(\text { NOS): } \\
\text { Non-Clinical voice hearers felt } \\
\text { more in control of hallucinations } \\
\text { than clinical voice-hearers on self- } \\
\text { report. }\end{array}$ \\
\hline Daalman et al. & 2012 & $\begin{array}{l}\text { Quantitative: Task- } \\
\text { based. }\end{array}$ & $\begin{array}{l}\text { N=120 } \\
\text { Hallucinating and } \\
\text { Psychotic; } \\
\text { Hallucinating and } \\
\text { Non psychotic; } \\
\text { Non-hallucinating } \\
\text { controls }\end{array}$ & $\begin{array}{l}\text { Preater controllability of voices in } \\
\text { non-psychotic individuals with } \\
\text { AVH as rated on PSYRATS. }\end{array}$ \\
\hline $\begin{array}{l}\text { Sorrell, Hayward, } \\
\text { Meddings }\end{array}$ & 2010 & $\begin{array}{l}\text { Quantitative: } \\
\text { Questionnaire-based: }\end{array}$ & $\begin{array}{l}\text { N=32 Clinical } \\
\text { voice hearers } \\
\text { N=18 non clinical } \\
\text { voice hearers }\end{array}$ & $\begin{array}{l}\text { Perceived / Rated Control (NOS): } \\
\text { Greater emotional distance from } \\
\text { voices in those with clinical AVH } \\
\text { than non-clinical AVH as rated on } \\
\text { PSYRATS. }\end{array}$ \\
\hline
\end{tabular}

Table 1. Descriptions of voluntary control in the literature. Note that, while several qualitative studies have highlighted the existence direct control abilities, most quantitative studies have focused on either coping strategies or more general control abilities as rated by participants or by clinicians on general scales like the PSYRATS. 